\title{
Development Services of MEMS-CORE
}

\author{
Koji Homma* \\ MEMS-CORE Co. Ltd., 3-11-1 Akedouri, Izumiku, Sendai, Miyagi 981-3206, Japan
}

(Received November 5, 2017; accepted January 12, 2018)

Keywords: MEMS, application, sensor, development service, foundry service, industry-university cooperation

In this paper, the technology and business activities of MEMS-CORE, which was established in 2001 as a venture company of Tohoku University, will be reviewed. MEMS-CORE is successfully maintaining the business of development services with about 150 companies, including foreign companies. The Industry-University Cooperation Project provided much benefit to MEMS-CORE's business activities through the codevelopment of useful processing apparatus. Here, we define development services as development efforts in MEMS-CORE under contract between a customer and MEMS-CORE. Development services play an important role in the MEMS industry, the same as foundry services of manufacturing a product under contract with a customer.

\section{Introduction}

The application of MEMS sensors is continuously spreading into various fields including sports, robotics, medicine, and senior care. As a result, we often encounter the words "wearable sensor" and "trillion sensors". Such sensors had been developed using MEMS fabrication technology; moreover, MEMS sensor development is awaited in various fields, for example, continuous monitoring of social infrastructure or the prediction of natural disasters, autodriving technology, and Internet of Things. While MEMS devices look like semiconductor devices, they have many differences. The most marked difference between the two is that the semiconductor device is static while the MEMS device is dynamic. In order to achieve this dynamism, in one case, a MEMS device adopts a unique material that is never used in the semiconductor industry, or in another case, 3D manufacturing technology is used to make a MEMS device structure. As a result, in MEMS development services, more widespread knowledge and technology are needed than in semiconductor device development, and in some cases, the fabrication process is more difficult.

Figure 1 shows the industrial status of MEMS devices from research to production. Development services cover early phases, research, development, and trial manufacture, whereas foundry services cover mainly trial manufacture and mass production.

*Corresponding author: e-mail: homma@mems-core.com

http://dx.doi.org/10.18494/SAM.2018.1799 


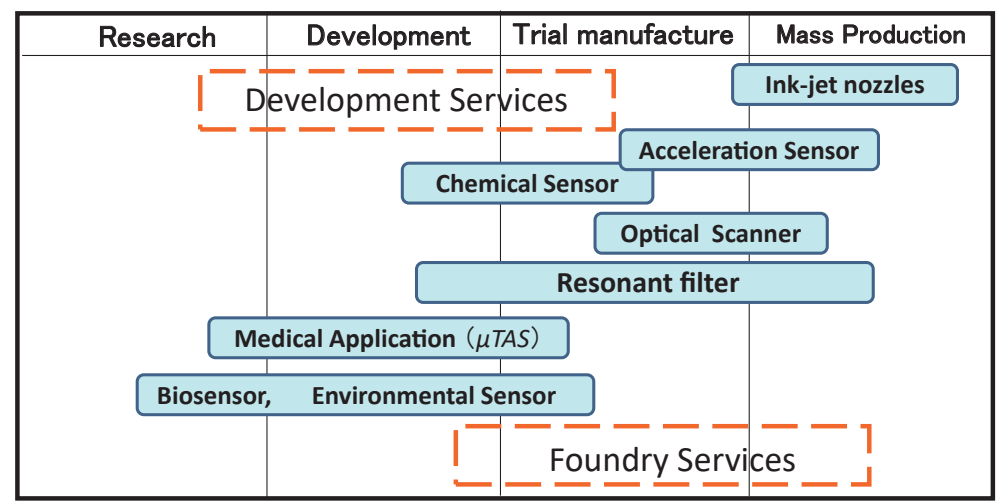

Fig. 1. (Color online) Development services and foundry services.

The most important, and, in many cases, the most difficult work is to show "what to make" not "how to make". Namely, in development services, the customer shows only the function they need, not the device structure. This is the basic difference from foundry services, in which a customer shows the device structure.

\section{Unique Technologies in MEMS Device Development and Development Services}

In MEMS devices, we must make a moving object and the space/structure for moving. Figure 2 shows the processing technologies of MEMS-CORE. MEMS-CORE has developed many unique processing technologies and accumulated much process know-how in-house, some of which will be described here.

\subsection{Deep Si etching}

Highly anisotropic plasma is exposed to a $\mathrm{Si}$ surface, and by repeating an etching and deposition cycle, a deep trench with vertical walls is formed in the Si substrate. This is the key technology in fabricating a device structure with moving space. In extreme cases, the trench reaches the back surface and is used for feed-through wiring.

\subsection{Sacrificial layer etching}

In many cases, a silicon-on-insulator (SOI) wafer is used for this process. For example, after making a Si pattern on silicon dioxide, etching off the underlying silicon dioxide results in an empty space that can be used for movement under the silicon.

\subsection{Glass-Si direct bonding (anodic bonding)}

In an optical MEMS device, we often adopt a glass cap over the silicon 3D structure. For such purposes, soda-lime glass is pressed against the silicon 3D structure under vacuum, and heated at around $300{ }^{\circ} \mathrm{C}$. When DC voltage $(\sim 500 \mathrm{~V})$ is applied (+ on $\mathrm{Si},-$ on glass), $\mathrm{Na}$ 


\begin{tabular}{|c|c|c|}
\hline Type & Process & Materials and equipment for the process \\
\hline \multirow{2}{*}{ Films } & $\begin{array}{l}\text { Formation of insulating } \\
\text { films }\left(\mathrm{SiO}_{2}, \mathrm{NSG}, \mathrm{PSG}\right)\end{array}$ & Oxidation furnace, AP-CVD, P-TEOS \\
\hline & $\begin{array}{l}\text { Formation of metal films } \\
\text { (Au, Pt, Cr, Ti, Cu, etc.) }\end{array}$ & Sputtering, EB deposition, MOCVD, electroplating \\
\hline \multirow{2}{*}{$\begin{array}{l}\text { Photolitho- } \\
\text { graphic }\end{array}$} & $\begin{array}{l}\text { Coating with resist } \\
\text { Exposure } \\
\text { Development }\end{array}$ & $\begin{array}{l}\text { Spinners, spray coaters (for early stages), laminators, } \\
\text { double-sided aligner, direct exposure equipment, } \\
\text { pattern generators }\end{array}$ \\
\hline & $\begin{array}{l}\text { Creating masters } \\
\text { (Cr masks) }\end{array}$ & CAD, pattern generators \\
\hline \multirow{2}{*}{ Etching } & Dry etching (of $\mathrm{Si}$ and $\mathrm{SiO}_{2}$ ) & $\begin{array}{l}\text { Deep RIE, RIE, ICP-RIE, sacrificial layers }\left(\mathrm{SiO}_{2}, \mathrm{Si}\right) \text {, } \\
\text { ionic milling, oxygen usher }\end{array}$ \\
\hline & $\begin{array}{l}\text { Wet etching (of } \mathrm{Si}, \mathrm{SiO}_{2} \text {, and } \\
\text { all kinds of metals) }\end{array}$ & TMAH, KOH, all kinds of metal-film etching liquids \\
\hline Connection & Connection to wafers & Anodic bonders, thermocompressive bonders \\
\hline \multirow{2}{*}{ Mounting } & Wafer cutting & Dicing tools \\
\hline & Bonding & Wire bonding \\
\hline Polishing & Wafer polishing & CMP, post-CMP cleaning \\
\hline Evaluation & & $\begin{array}{l}\text { Interferometric film-thickness meters, stylus-type profilometers, } \\
\text { SEM-based sheet-resistance meters, stress meters, measuring } \\
\text { microscopes }\end{array}$ \\
\hline Other processes & Blast processing & Sandblasting \\
\hline $\begin{array}{l}\text { Other dry } \\
\text { processes }\end{array}$ & Cleaning, Surface modification & $\begin{array}{l}\text { UV/ozone processing, room-temperature plasma surface } \\
\text { processing, HMDS coating }\end{array}$ \\
\hline
\end{tabular}

Fig. 2. (Color online) Processing technologies of MEMS-CORE.

ions in the glass migrate toward the interface to form an electrical double layer with electrons in $\mathrm{Si}$, resulting in attractive force between glass and $\mathrm{Si}$. By maintaining this condition for approximately $30 \mathrm{~min}$, glass-Si direct bonding is achieved.

\subsection{Unique materials}

Various piezoelectric materials, inorganic materials with special optical characteristics, and plastics can be used for various purposes.

Figure 3 shows a correlation diagram between sensor functions, materials, and applications in MEMS devices. Figure 4 shows an example of a flow chart of development services at MEMS-CORE. Meeting the customer's request, university support, and collaboration with a mass-production partner and system house are important. In this example, starting with the customer's request, we perform the following four steps and finally deliver the prototype to the customer.

Step 1: Create the product image based on the customer's request

On the basis of wide market/technology research, create a device structure of the product that meets the customer's request.

Step 2: Design

Prepare drawings of the prototype and determine the process recipe. 


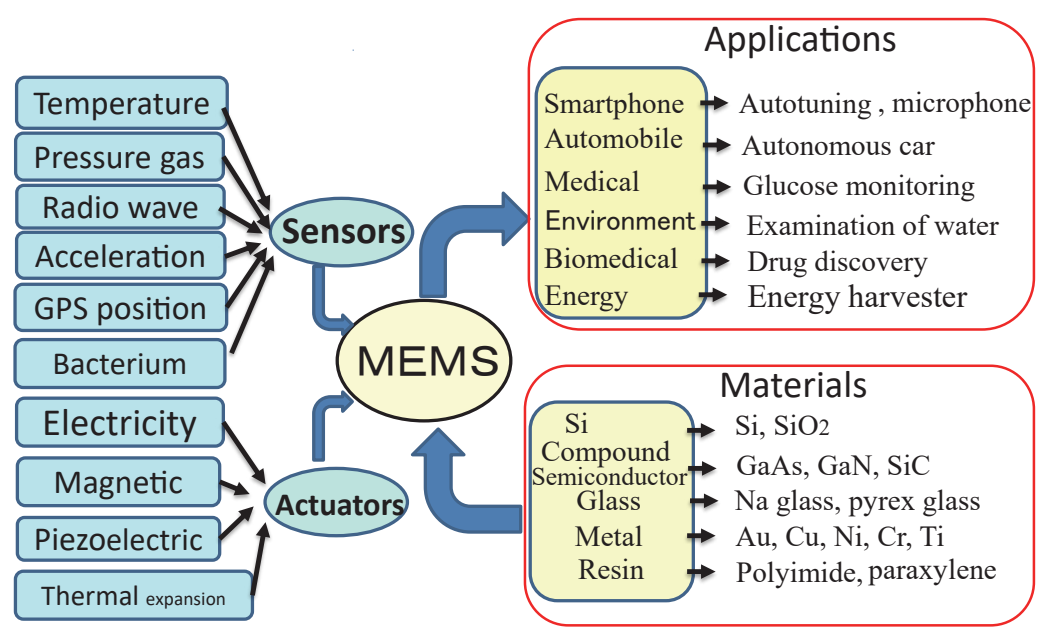

Fig. 3. (Color online) Functions, materials, and applications of MEMS.

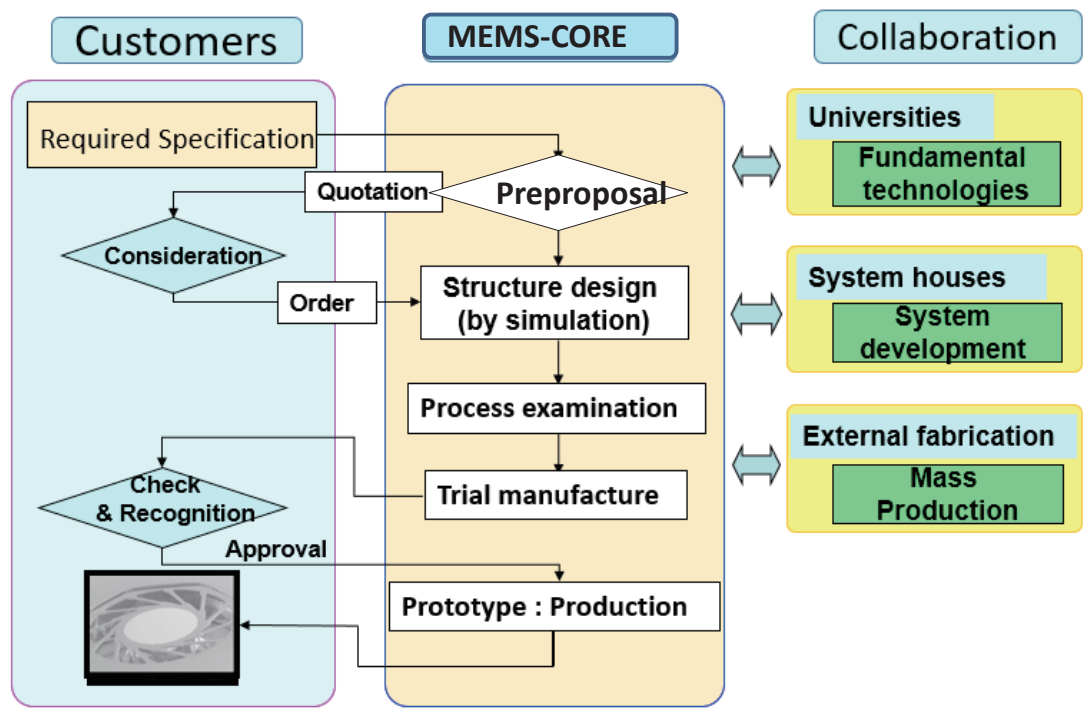

Fig. 4. (Color online) Flow chart of development services.

Step 3: Prototype fabrication, bonding, and packaging

Purchase the materials needed and present a suitable process/treatment to make a prototype.

Step 4: Evaluation and characterization

In many cases, the aim of a customer's request is to greatly exceed the products already on the market, which is the reason why development services are difficult.

\section{Industry-University Cooperative Project and Development Services}

In development services, we must always pursue technological progress in order to develop better products at minimum development cost. The challenge of adopting new materials or 
highly difficult processes is important. In such cases, university support is very effective because a university already has much knowledge and know-how of the physical and chemical properties of new materials, as well as safety know-how.

The development subjects are categorized into two groups:

(1) subjects that can be manufactured by existing process technology, and

(2) subjects that require the development of new process technology including new materials.

In case (2), we ask university staff to support the new driving principle, new material, and its processing method. In addition, we obtain support to develop dedicated equipment for special processing.

Figure 5 shows the equipment that we use daily in development services; $70 \%$ of them are the same as those used in semiconductor processing, but the rest are dedicated MEMS processing equipment. Such dedicated equipment is truly the key equipment in pursuing development services. In particular, machines developed in cooperation with Tohoku University, marked with the $\mu$ SIC logo, are excellent because they are designed on the basis of wide and extensive research result, and improved by continuous experiment and feedback. They are now key players in development services. Here, some examples will be described in greater detail.

Figure 6 shows the PZT film formation machine (sol-gel method) which is utilized in sensor/ actuator fabrication. The process flow is a repeatitive cycle comprising spin-coating of the source material and drying at $200{ }^{\circ} \mathrm{C}$, followed by pyrolysis at $350{ }^{\circ} \mathrm{C}$. The number of cycles depends on the needed thickness. Finally, rapid thermal annealing is applied to crystallize the film [source material (product of Mitsubishi Materials) $\mathrm{ZrO}_{2}: \mathrm{TiO}_{2}: \mathrm{PbO}=52: 48: 110$ in mol].

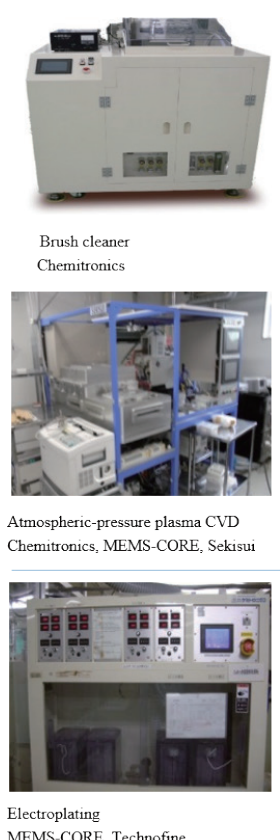

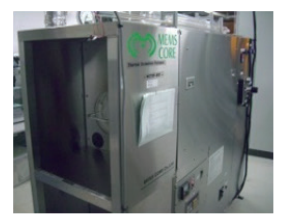

Si oxidation furnace

Si oxidation furnace
Chemitronics, MEMS-CORE

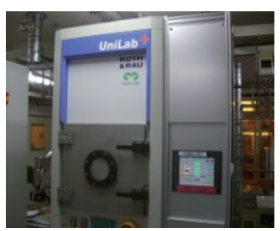

Gas plasma etcher

MEMS-CORE, Roth \& Rau

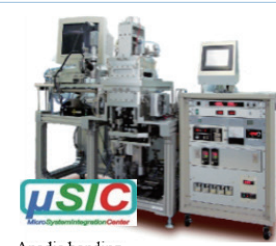
Anodic bonding
Chemitronics

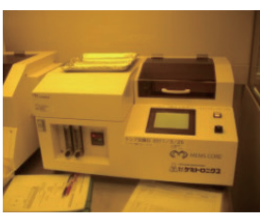
UV-ozone cleaner

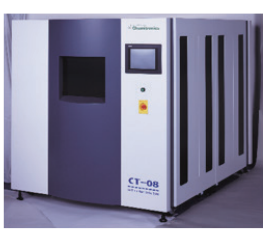

Sacrificial layer etcher Chemitronics

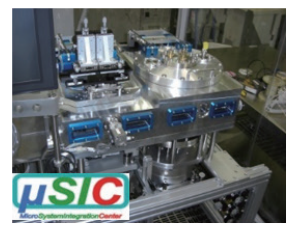

Si-Si low temperature bonding Technofine, Tohoku Univ.

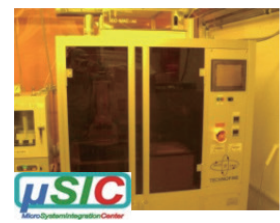
Chemitronics

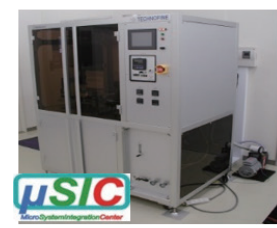

PZT film formation machine Tohoku Univ, Technofine

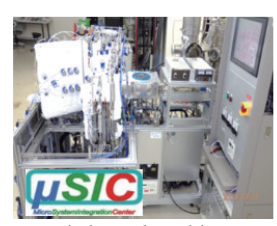

Atomic layer deposition Technofine, MEMS-CORE

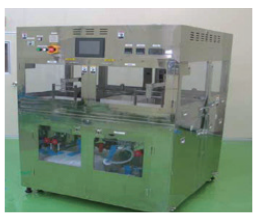

Anisotropic dry etcher

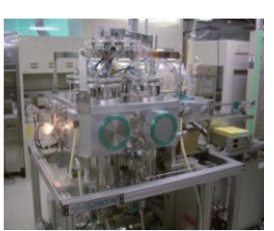

Multisource sputtering MEMS-CORE, Technofine

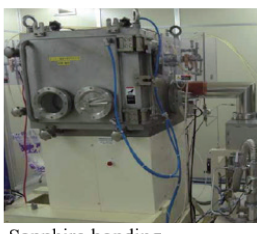

Sapphire bonding Chemitronics

Fig. 5. (Color online) Custom-made processing machines. 


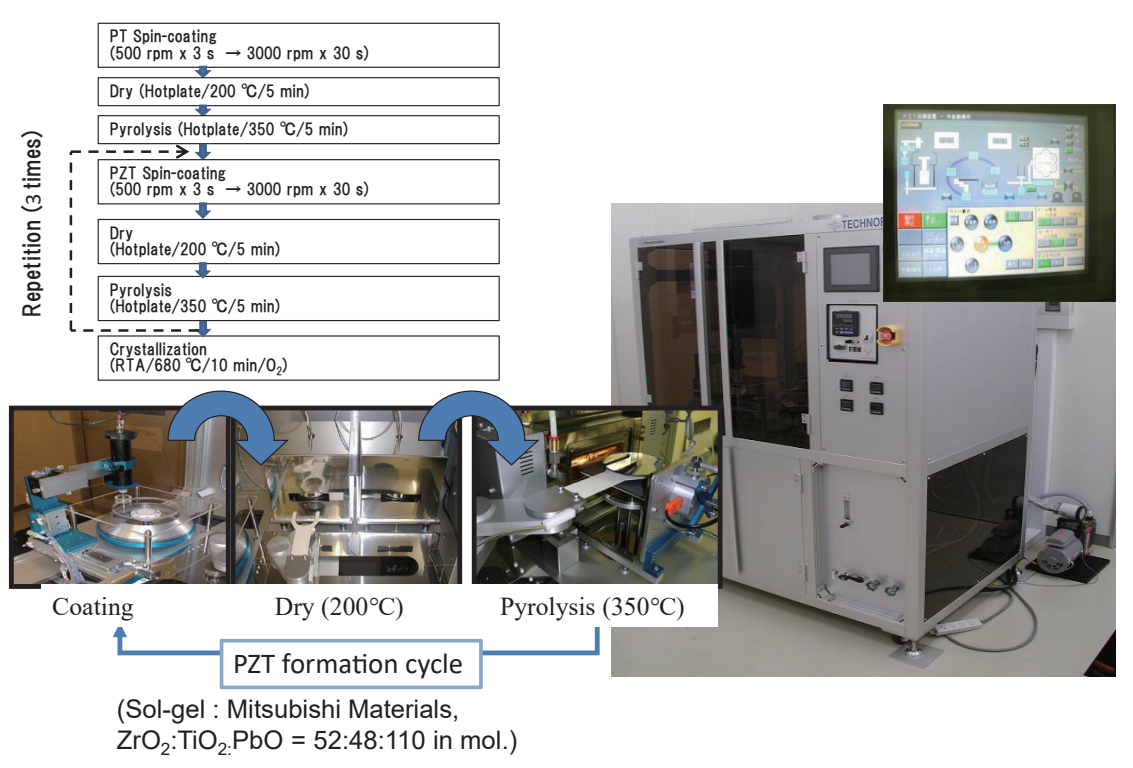

Fig. 6. (Color online) PZT film formation machine (sol-gel method).

Figure 7 shows the sacrificial etching machine. In this process, the $\mathrm{SiO}_{2}$ film is etched off at a much higher rate than the Si film, resulting in a comb-shaped Si structure. The two images in the bottom left show the $\mathrm{Si}$ comb pattern after etching of the underlying $\mathrm{SiO}_{2}$ (sacrificial layer). Conventional wet etching results in sticking between Si combs when etchant is evaporated owing to the surface tension of the etchant. On the other hand, because our machine provides all-dry processes free of sticking. This machine features an antisticking function involving $\mathrm{SiO}_{2}$ dry etching followed by hydrofluoric material treatment in situ.

Figure 8 shows an anodic-bonding machine with an alignment function. For optical device fabrication, a glass window is often adopted; in such a case, this machine is useful for achieving glass-Si bonding under vacuum or special gas ambient. This machine also has a plasma surface treatment function, which results in stable anodic bonding.

Figure 9 shows an atomic layer deposition (ALD) apparatus. This machine will be utilized for various processes including the deposition of functional thin films such as catalysts, deposition of insulating film inside a through Si via (TSV), development of an ultrathin insulating film, and development of a magnetic thin-film sensor.

\section{Example of Cooperation with University: Low-temperature Si-Si Bonding}

On the basis of research results from Prof. Tanaka's laboratory in Tohoku University, we have developed a low-temperature $\mathrm{Si}-\mathrm{Si}$ bonding machine. $\mathrm{Sn}-\mathrm{Cu}$ thin film transient liquid phase (TLP) bonding was investigated using this machine. ${ }^{(1)}$ Here, some details are presented. 


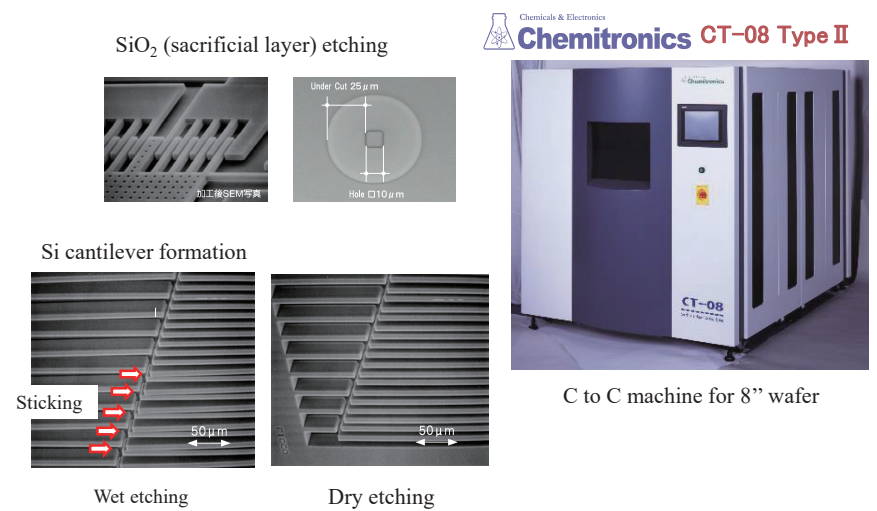

Fig. 7. (Color online) Sacrificial etching machine.

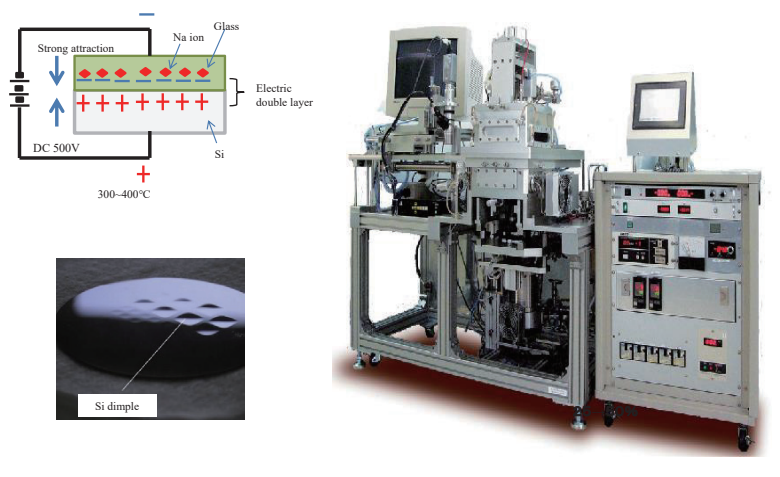

Fig. 8. (Color online) Anodic bonding machine.

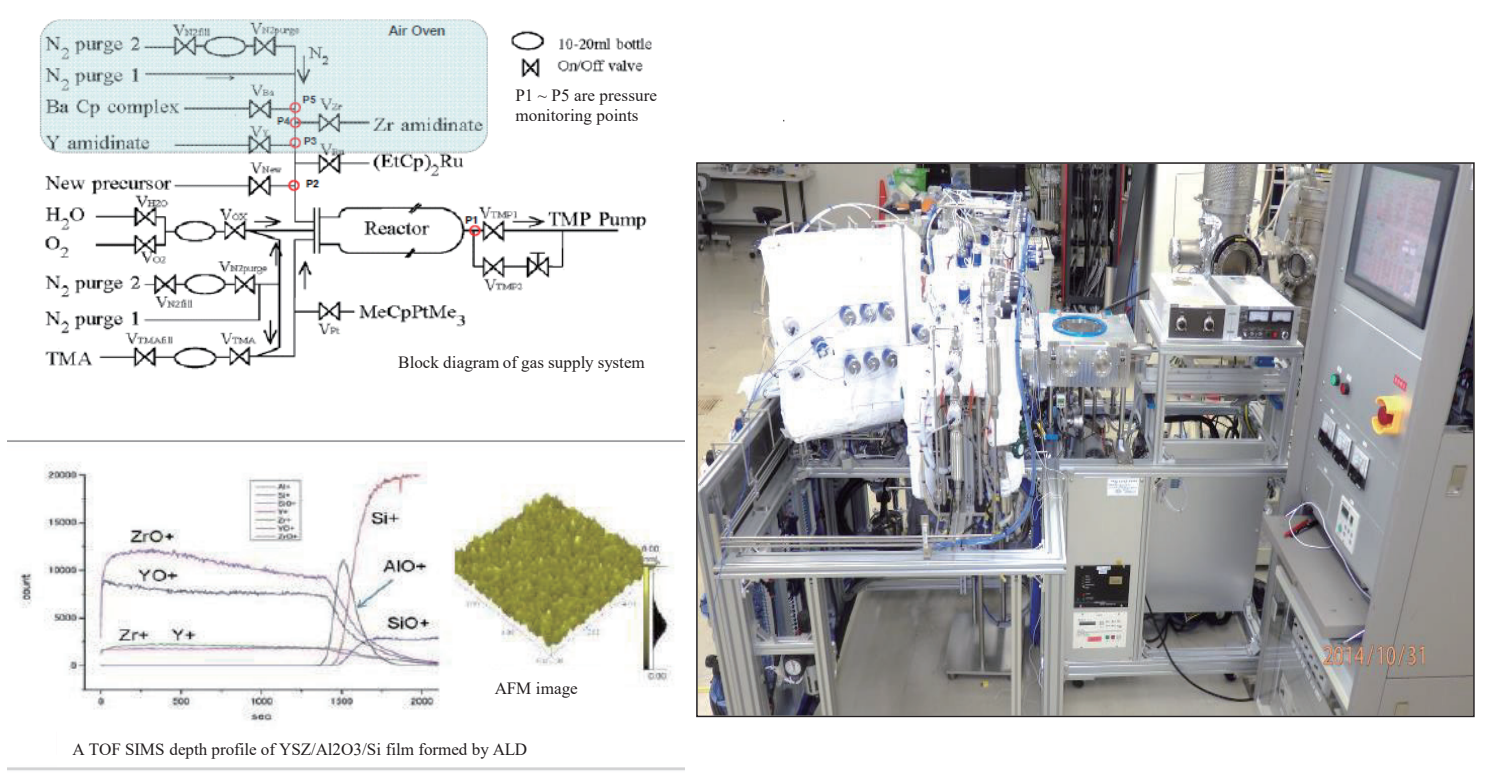

Fig. 9. (Color online) ALD.

\subsection{Development of in-house bonding machine}

Figure 10 shows (a) the bonding machine, (b) close-up of multiple pistons, (c) drawings of wafer-handling mechanism, and (d) result of pressure distribution evaluation. This machine enables surface treatment with formic acid, alignment, and bonding successively in vacuum. ${ }^{(2)}$ The material selection for each part is important, especially hardness. We adopted sapphire for the top and bottom plates, SUS304+ Cu (to obtain temperature uniformity) for the bottom stage, and SUS420 for upper and transfer stages. High-frequency annealing was applied to SUS420; as a result, its Rockwell hardness (HRC) is higher than 45. The wafers to be bonded are supported on sapphire plates with thin plate springs, and handled by a transfer mechanism. Wafer alignment is carried out under infrared cameras; then, wafer bonding is carried out under 


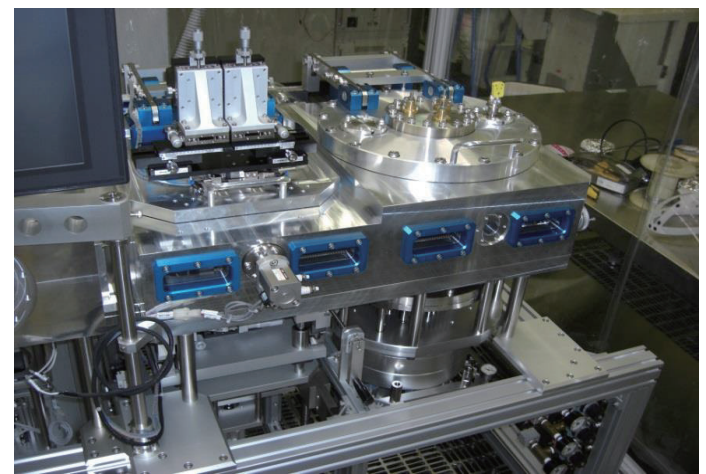

(a)

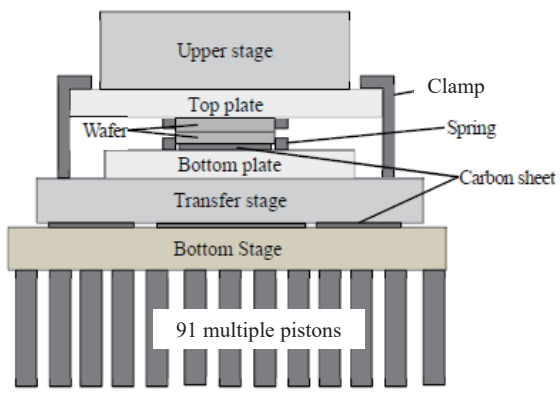

(c)

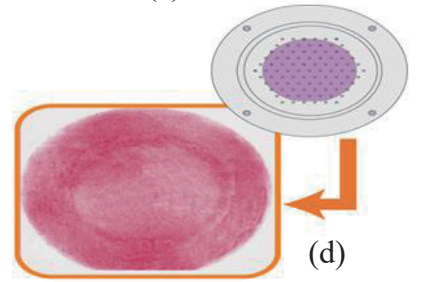

Result of pressure distribution evaluation

Fig. 10. (Color online) Si-Si low-temperature bonding machine.

uniform pressure applied by the multiple piston mechanism illustrated in Fig. 10(c). In addition, a carbon sheet placed under the wafer and transfer stage provides more uniform pressure distribution. To avoid metal interdiffusion before bonding, wafers should be heated quickly. Thus, the wafers are loaded into the bonding mechanism that is preheated to $400{ }^{\circ} \mathrm{C}$. A bonding pressure of $49 \mathrm{MPa}$ is applied to the wafer set. Temperature and pressure are maintained for 60 min. The bonded sample is taken out from the chamber after cooling to $100{ }^{\circ} \mathrm{C}$ in $\mathrm{N}_{2}$ ambient.

\subsection{Evaluation results of $\mathrm{Sn}-\mathrm{Cu}$ thin film TLP bonding.}

Six samples with different underlayers were compared. The underlayer consists of a $\mathrm{Cr}$ adhesion layer and a multilayer diffusion barrier of $\mathrm{Cr} / \mathrm{Cr}$, and mixed $\mathrm{Cr}-\mathrm{Cu}$ or $\mathrm{Ni}$. Without the barrier layer, the shear bonding strength is smaller. If thermal cycling is applied or $\mathrm{Cu}$ is thinner, a larger drop in the bonding strength may occur without the barrier layer. The bonding strength just after bonding shows no significant difference among the three kinds of barrier layers. The best result is obtained using a $\mathrm{Au} / \mathrm{Sn} / \mathrm{Cu} / \mathrm{Cr}-\mathrm{Cu} / \mathrm{Cr}$ metal system $(10 / 200 / 1000 / 100 / 100$ $\mathrm{nm}$ ), where the $\mathrm{Cu}$ thickness is doubled compared with the other samples. Now, we are considering the commercialization of this alignment/bonding machine in the near future.

\section{Business Summary}

To date, MEMS-CORE has carried out contracted development services with about 150 customers. A review of previous development services has revealed that in the case of development with existing technologies, the development could be completed in 3 months. However, when development requires device structure design, material search, and process 
development, the development takes 12-18 months. To avoid the cost risk, our management requires a milestone every 3 months; namely, every 3 months, we review the development results, and discuss with the customer whether to proceed further.

Figure 11 shows the customer distribution; almost $70 \%$ of customers are from Tokyo and Osaka areas (Kanto and Kansai districts), and Tohoku customers comprise less than $10 \%$ even through MEMS-CORE is located in Tohoku. Foreign customers from the U.S. and China comprise less than $10 \%$, but recently, the number of inquiries has been increasing. Figure 12 shows the technology distribution. The number of subjects related to the semiconductor industry is decreasing, whereas the number of the subjects related to bioscience, environment, and communication industry is increasing. The total demand for development services is expected to grow continuously in the future. From the financial viewpoint, MEMS-CORE became profitable in 2012, 11 years after its establishment. Subsequently, business growth had become constant. Further growth is expected in the trillion sensor era.

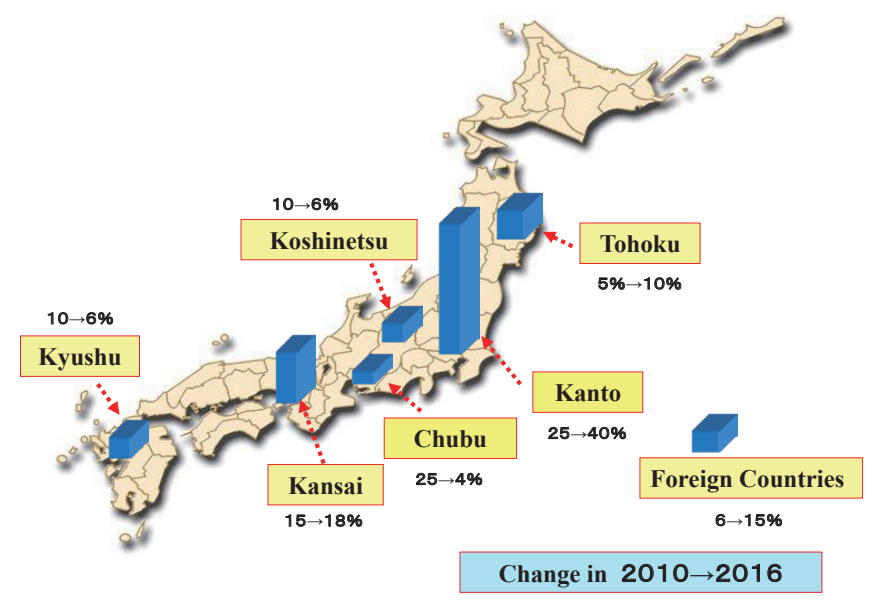

Fig. 11. (Color online) Customer distribution.

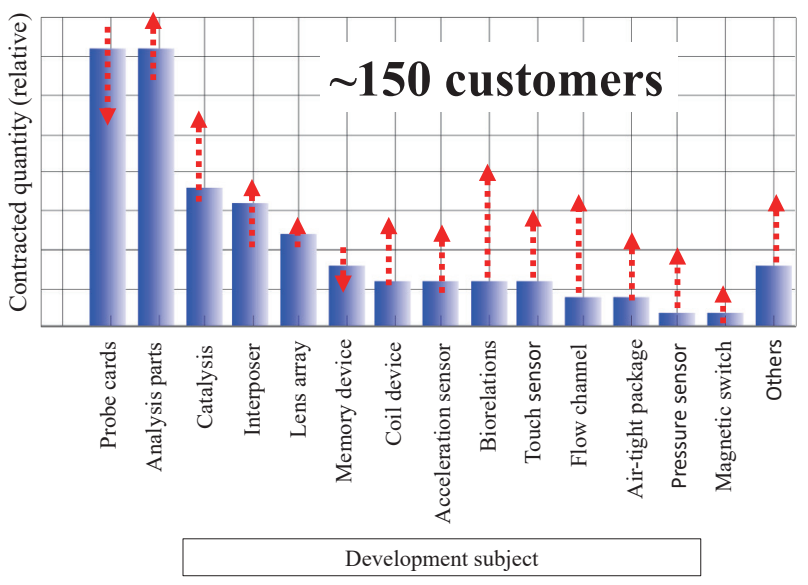

Fig. 12. (Color online) Technology distribution in development services. 


\section{Future Forecast}

MEMS-CORE has been continuing development services as a business and became profitable several years ago. During the last 15 years, customer demand was always changing, reflecting the changes in society. In particular, the rapid spread of the smart phone and autodriving technology development are major topics that demand MEMS sensors of higher quality and precision, as well as a shorter technology development period.

\section{Acknowledgments}

MEMS-CORE's technological effort during development services with more than 150 customers over the past 15 years has resulted in great technological advances in MEMS-CORE. That is a great feature of MEMS-CORE. MEMS-CORE extends its sincere appreciation to all customers. MEMS-CORE sincerely appreciates Professors Masayoshi Esashi, Shuji Tanaka, Takahito Ono, and Kazuhiro Hane, all of Tohoku University, for their support. We would like to ask for your continuing support and, at the same time, we promise to continue our efforts in development services to provide high-quality and new MEMS devices to all customers.

\section{References}

1 K. Hikichi, S. Matsuzaki, Y. Nonomura, H. Funabashi, Y. Hata, M. Esashi, and S. Tanaka: Proc. 2014 IEEE Int. Frequency Control Symp. (IEEE, 2014) 246.

2 S. Matsuzaki, S. Tanaka, and M. Esashi: IEEJ Trans. SM 131 (2011) 189. 